\title{
Perception of Use of Herbal and Orthodox Medicines in Parts of Abuja: A Pilot Study
}

\author{
Kudirat Bola Mustapha ${ }^{1 *}$, Rukaiyatu Abdullahi Kirim ${ }^{1}$, Jemilat Aliyu Ibrahim², Philip U. Onuche ${ }^{1}$, \\ Moji Taibat Bakare-Odunola ${ }^{3}$ \\ ${ }^{1}$ Department of Medicinal Chemistry and Quality Control, National Institute for Pharmaceutical Research and Development (NIPRD), PMB 21, Abuja, \\ Nigeria., ${ }^{2}$ Department of Medicinal Plant Research and Traditional Medicine, National Institute for Pharmaceutical Research and Development (NIPRD), \\ PMB 21, Abuja, Nigeria., ${ }^{3}$ Department of Pharmaceutical and Medicinal Chemistry, Faculty of Pharmaceutical Sciences, University of Ilorin, Ilorin, \\ Nigeria.
}

\begin{tabular}{l} 
ARTICLE INFO \\
\hline Article history: \\
Received on: $29 / 01 / 2016$ \\
Revised on: 03/03/2016 \\
Accepted on: 23/05/2016 \\
Available online: $26 / 09 / 2016$ \\
\hline Key words: \\
Herbal, Orthodox, Medicine, \\
Respondents, Adverse Effect.
\end{tabular}

\section{INTRODUCTION}

Herbal and Orthodox medicines are two main types of medicines that are well known and widely used in Nigeria. Herbal medicines are products made from plant, plants or part of plant which can be in the form of juices, gums, fatty oil, stem and root bark, leaves, fruits, etc (Elujoba, 1998) and they can be purchased in bulk in the crude form or as refined pharmaceutical dosage form such as Capsules, tablets, concentrated extracts, teas, tinctures and decoction (Barnes, 2003). According to WHO herbal medicine is defined as finished labeled medicinal products that contains as active ingredient aerial or underground parts of plants or other plant materials or combinations there of

\footnotetext{
* Corresponding Author

Department of Medicinal Chemistry and Quality Control, National Institute for Pharmaceutical Research and Development (NIPRD), PMB 21, Abuja, Nigeria.Email: bolakud @ yahoo.com
}

whether in the crude state or as plant preparations (WHO,1996). On the other hand, Orthodox medicine may be defined as any substance of vegetable animal or mineral origin or any preparation or admixture thereof or chemical compounds which are used for internal or external application to the human body in the treatment of diseases (Bodecker, 1995). The current global interest in herbal medicines and high dependence on it is perhaps a measure of the realistic perception of the limitations of orthodox medicines in terms of cost, accessibility, effectiveness and safety (Moody, 2007).

And the use of herbal medicines in the treatment and prevention of diseases is attracting attention by scientists all over the world which is also corroborated by World Health Organization in its quest to bring primary health care to the people. Herbal products have been reported to be less concentrated, less toxic and more natural. They are unlike orthodox medicines which are concentrated drug formulations. 
Also, in African setting, herbal medicines are generally said to remedy disrupted physiological processes in the body rather than targeting diseases whereas orthodox medicines are designed to target and reverse specific pathologies in the minimum time (Ohuabuna, 1998 \& Moody, 2007).

There are several publications on the estimated percentage of people in the developing world using traditional medicine (Bodecker, 1995) but there have not been any study to document the actual number in Nigeria. Also the perceptions and preference of orthodox and traditional medicine usage in Nigeria have also not been documented locally despite several referrals to developing countries when discussing the issue in literatures. This study assessed the perceptions and preference of use of herbal and orthodox medicines in Abuja.

\section{MATERIALS AND METHODS}

\section{Description of Study Site}

Abuja is the Federal Capital of Nigeria that is strategically situated in the center of the country. It lies above the hot and humid low lands of the Niger and Benue rivers. Abuja is made up of six Areas Councils namely; Abaji, Abuja Municipal, Bwari, Gwagwalada, Kuje and Kwali. The inhabitants of the Abuja countryside are predominantly farmers. Their main language is Gwandara. The FCT has borders on the north with Kaduna State, on south-east with Nasarawa State, on the southwest by Kogi State and on the west by Niger state. The entire Federal Capital Territory occupies an approximate land area of 8,000 square kilometers (AGIS, 2004).

\section{Study site}

The Study covered five major areas in Abuja municipal area council (AMAC). These areas were Area 10 (Garki), Central Business District, Idu Industrial Area, Lugbe and Wuse Zone 5 (Table 1).

Table 1: List of Study sites, Number of questionnaires administered and percentage of response.

\begin{tabular}{lcc}
\hline Study Sites in FCT & $\begin{array}{c}\text { No of Questionnaire } \\
\text { Administered }\end{array}$ & $\begin{array}{c}\text { No of Response } \\
\text { and \% Response }\end{array}$ \\
\hline Area 10, Garki & 50 & $50(100 \%)$ \\
Central Business district & 50 & $50(100 \%)$ \\
Idu Industrial Area & 30 & $26(86.67 \%)$ \\
Lugbe & 50 & $50(100 \%)$ \\
Wuse, Zone 5 & 20 & $20(100 \%)$ \\
Total & $\mathbf{2 0 0}$ & $\mathbf{1 9 6 ( 9 8 . 0 \% )}$ \\
\hline
\end{tabular}

\section{Administration of Questionnaires}

Questionnaires were administered to respondents and the questionnaire comprises questions on Personal data (age range and sex, etc.) and core issues like preferences, reasons for the choice of medicine, affordability, packaging, first-aid, recommendation, advertisement, diseases treated, adverse effect and efficacy.

Questions were also raised on whether the respondents used herbal medications alongside orthodox medicines at one time or the other; whether the diseases treated with herbal medicines were partially or completely cured and if any adverse effects. For the purpose of some respondents who can neither read nor write, oral interview was conducted for them in order to get their own opinion. Prior Informed Consent of the respondents was obtained before the commencement of the interview or administering of the questionnaires.

Two hundred questionnaires were administered with fifty respondents each from Garki Area 10, Central Business Area and Lugbe; while thirty respondents from Idu Industrial Area and twenty from Wuse Zone 5 (Table 1).

Out of the 200 questionnaires administered, four were not returned by the respondents, hence a total of one hundred and ninety-six were eventually analysed for the study. The Respondents includes passengers in buses, market women, civilservants, National Youth Service Corp members, students and traders.

Data were analyzed using descriptive statistics while the t- test statistic which is an interferential tool (SPSS 19) was employed to test the significant different between the means of the variables that were tested to do a comparative assessment of some of the attributes of herbal and orthodox medicines at $5 \%$ level.

\section{RESULTS AND DISCUSSION}

The study sites, number of questionnaires and the percentage response for the use of herbal products and orthodox medicine for the studied population are illustrated in table 1 . Table 2 showed the gender, age, frequency and the percentage distribution of population. $98 \%$ of the questionnaire were responded to, while four respondents from Idu Industrial area did not return the questionnaires as showed in table 2 .

From the 196 respondents, $112(57.14 \%)$ were males while $77(39.29 \%)$ were females and 7 (3.57\%) did not indicate their sex.The highest number (118) of respondents is within the age range of $21-35$ which is about $60.28 \%$, followed by those in the age range of 36 years and above, which is $52(26.28 \%)$, then 15 -20years had $19(9.69 \%)$ while the least number of respondents was from the age range of 15 years and below (Table 2).

Table 2: Demographic Variable Frequency and Percentage.

\begin{tabular}{lcc}
\hline Gender & Frequency & Percentage (\%) \\
\hline Male & 112 & 57.14 \\
Female & 77 & 39.29 \\
Not indicated & 7 & 3.57 \\
\hline Total & $\mathbf{1 9 6}$ & $\mathbf{1 0 0}$ \\
\hline Age(Years) & Frequency & Percentage (\%) \\
\hline Below 15 & 6 & 3.06 \\
$15-20$ & 19 & 9.69 \\
$21-35$ & 118 & 60.28 \\
$36 \&$ above & 52 & 26.53 \\
Not indicated & 1 & 0.51 \\
\hline Total & $\mathbf{1 9 6}$ & $\mathbf{1 0 0}$ \\
\hline
\end{tabular}

Figure 1 depicts the preference of the use of herbal product and orthodox medicine, more so, $41.33 \%$ of the respondents liked the packaging of herbal medicines, $57.65 \%$ disliked it and 1.02\% did not indicate either as shown in Fig.2. 


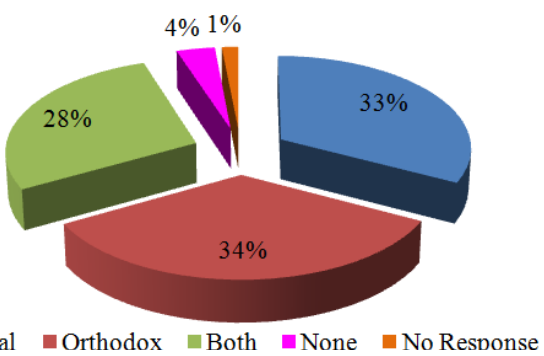

- Herbal Orthodox Both None No Resnonse

Fig. 1: Percentage Response for the Use of Herbal Products and Orthodox Medicine.

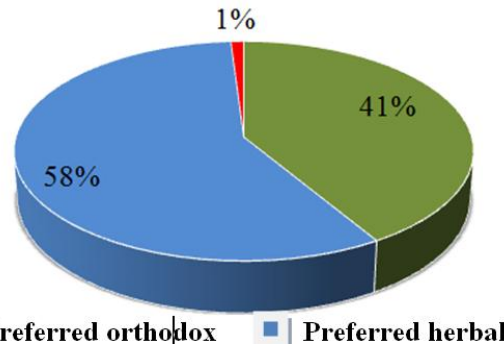

Fig.2: Respondents opinion on the packaging of herbal and orthodox medicines

The respondents' opinion on affordability of herbal products and orthodox medicine are illustrated in figure 3.The Respondent First Choice of Medicine for Treatment of an Ailment is illustrated in figure 4 while figure 5 showed the respondents choice on the medicine that can be recommended for use.

In terms of adverse effect, $10.77 \%$ of the respondents reported that they experienced adverse effect after taken herbal product but $72.96 \%$ said they didn't experience any adverse effect, while $16.31 \%$ said they haven't used herbal medicines before (Fig. 8). Out of the 200 questionnaires administered, four were not returned by the respondents, hence a total of one hundred and ninety-six were eventually analyzed for the study. The Respondents includes passengers in buses, market women, civilservants, NYSC members, students and traders. The overall rate at which the Respondents responded to the questionnaire was $98 \%$ (Table 1): The four respondents who did not return the questionnaires were all from one location (Idu Industrial area). Out of the 196 respondents, $112(57.14 \%)$ were males while 77 $(39.29 \%)$ were females and $7(3.57 \%)$ did not indicate their sex (Table 2).

Also, respondents within the age range of 21-35 years have the highest number of $118(60.28 \%)$, followed by those in the age range of 36 years and above $52(26.58 \%)$, then $15-20$ years had $19(9.69 \%)$ while the least number of respondents was from the age range of 15 years and below (Table 2).

More so, $41.33 \%$ of the respondents liked the packaging of herbal medicines, $57.65 \%$ disliked it and $1.02 \%$ did not indicate either (Fig. 1). 33\% of the respondents prefer herbal medicines alone, $34 \%$ indicated that they prefer orthodox medicines whereas $28 \%$ prefer both herbal and orthodox medicines for treatment. However, $4 \%$ said they neither take orthodox medicines or herbal medicine and $1 \%$ did not indicate (Fig.2).

Some comparisons were made between herbal and orthodox medicines in terms of affordability with $58.16 \%$ respondents said herbal product is more affordable, $40.31 \%$ said orthodox medicines are more affordable while $1.53 \%$ did not respond (Fig. 3)

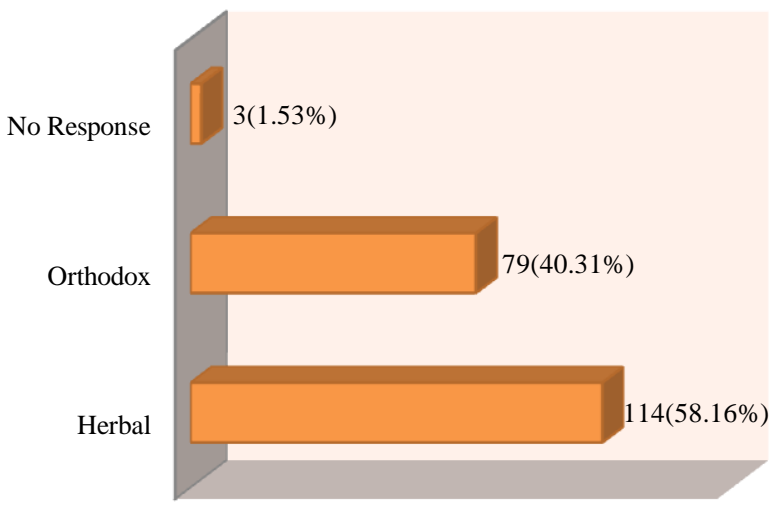

Fig. 3: Respondents' opinion on the medicine more readily affordable.

In response to the question of what type of medicine will occur to the respondent to use in terms of first-aid for emergencies, $28.06 \%$ indicated that they will go for herbal medicines, $70.41 \%$ said orthodox medicines, $1.53 \%$ did not indicate if they will go for anyone in times of emergencies (Fig. 4).

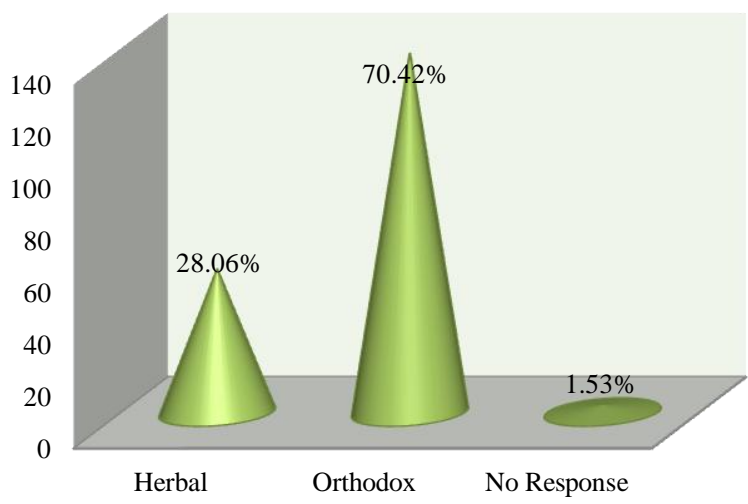

Fig. 4: Respondent First Choice of Medicine for Treatment of an Ailment.

More so, $41.48 \%$ were of the opinion that they will recommend herbal medicines for their family and friends while $56.12 \%$ said they would rather recommend orthodox medicines and $2.04 \%$ did not indicate which they will recommend (Fig.5).

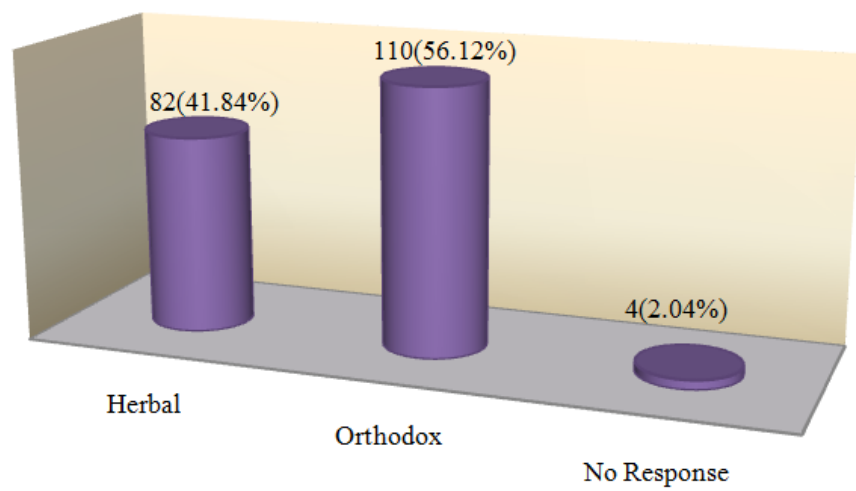

Fig. 5: Respondents choice on the medicine that can be recommended for use 
Table 3: T-Test Pairs $=$ Herbal with Orthodox (PAIRED).

Table 3a: Paired Samples Statistics.

\begin{tabular}{cccccc}
\hline & & Mean & N & Std. Deviation & Std. Error Mean \\
\hline \multirow{2}{*}{ Pair 1 } & Herbal & 78.75 & 4 & 26.043 & 13.022 \\
\cline { 2 - 6 } & Orthodox & 96.00 & 4 & 34.303 & 17.151 \\
\hline
\end{tabular}

Table 3b: Paired Samples Correlations.

\begin{tabular}{ccccc}
\hline & N & Correlation & Sig. \\
\hline Pair 1 & Herbal \& Orthodox & 4 & -0.551 & 0.449 \\
\hline
\end{tabular}

Table 3c: Paired Samples Test.

\begin{tabular}{|c|c|c|c|c|c|c|c|c|c|}
\hline & & \multicolumn{5}{|c|}{ Paired Differences } & \multirow{3}{*}{$\mathbf{t}$} & \multirow{3}{*}{ df } & \multirow{3}{*}{ Sig. (2-tailed) } \\
\hline & & \multirow[t]{2}{*}{ Mean } & \multirow[t]{2}{*}{ Std. Deviation } & \multirow{2}{*}{$\begin{array}{l}\text { Std. Error } \\
\text { Mean }\end{array}$} & \multicolumn{2}{|c|}{$\begin{array}{l}\text { 95\% Confidence Interval of the } \\
\text { Difference }\end{array}$} & & & \\
\hline & & & & & Lower & Upper & & & \\
\hline Pair 1 & Herbal - Orthodox & -17.250 & 53.281 & 26.641 & -102.033 & 67.533 & -0.648 & 3 & 0.563 \\
\hline
\end{tabular}

With respect to the level of advertisement both in the print and electronic media, $40.82 \%$ said the level of advertisement is very low, $42.86 \%$ said it's high, whereas $14.80 \%$ indicated that it was very high (Fig. 6).

Also in term of the degree at which herbal medicines cures, $17.35 \%$ of the respondents indicates that they were partially cured or relieved of the symptoms of the ailments while $65.82 \%$ indicated that they were completely cured of the symptoms of the ailments. $16.84 \%$ said they have never used herbal medicines for treatment of any ailments and therefore cannot give a specific answer (Fig.7). In terms of adverse effect, $10.77 \%$ of the respondents testified that after their use of herbal medicines, they experienced adverse effect but $72.96 \%$ said they didn't experience any adverse effect, while $16.31 \%$ said they haven't used herbal medicines before (Fig. 8). Contrary to the widespread view that because herbal medicine is natural and therefore very safe: Vickers (1999) and Anonymous (1986) believed that herbal therapy probably carries more risks and causes more side-effects than any other form of alternative therapy. Unfortunately, there are scanty information on the incidence of acute/ severe side-effects, such as liver failure, mutagenicity and carcinogenicity after certain herbal medications have been used (Langmead and Rampton, 2001).

From the results above, it was observed that higher percentage of respondents rated orthodox medicines higher than herbal medicines in terms of first-aid packaging and recommendation. Their opinion was backed up with reasons being that orthodox medicines are well prepared, their purity was ascertained and that have specific dosage form and hence stops overdose of drugs which are general opinions. On the other hand, respondents prefer herbal medicines in the sense that they are of natural origin and hence do not have much effect on the body's chemistry they also believe that herbal medicines cure illness completely and even go extra miles in nourishing the body (Contable et al, 2007 and King, et al, 2009). The poor perceptions of packaging of herbal medicines have been a major problem in the use of herbal medicines especially in the developing world. This is an area that needs serious improvement if herbal medicines have to be accepted by a large number of the population. This perception was also confirmed in this study where only about $41 \%$ of the respondents liked the packaging of herbal medicine whereas over 58\% like packaging of orthodox medicines better (Fig.2). Another issues plaguing the developing World including Nigeria is the over exaggeration of Traditional Medicine Practitioners (TMPs) or herbal medicine producers on their product being able to cure all ailments. This will also affect the level of acceptance of any medicine especially by the elites of the society who believed that one drug cannot cure all ailments. According to the WHO, over $80 \%$ of the world's population depends on traditional medicines for its primary health care (Bodecker, 1995). The result obtained from this work also showed that about $61 \%$ (33\% of those who preferred herbal medicine and $28 \%$ that preferred both) of the total study group can be said to use herbal medicines for treatment of ailments. The percentage might even be close to WHO estimate or higher if a larger population was used for this study, and the rural areas covered as the locations for this study were mainly of urban settings. The statistical paired sample test for Differences in the means of attributes of herbal and orthodox medicines survey indicates that the means were not Significant at $\mathrm{P}>0.05$, the significant (2-tailed) value in the result of the test is 0.563 which was greater than 0.05 (Table $3 \mathrm{c}$ ).

\section{CONCLUSION}

In conclusion, even though orthodox medicines are widely used, some people still prefer herbal medicines because of their natural states. But as a result of some reasons such as packaging, method of preparation and awareness campaign, they prefer to continue with the use of orthodox medicines. Although the study was conducted in a community where residents are mainly elites, the high percentage of respondents using herbal medicines in preference to orthodox medicine is a supporter to the acclaimed statement that $80 \%$ of developing countries populace depends on herbal medicine for treatment of ailments. This work is an eye opener for the herbal medicines practitioners' to improve on packaging and standardization of their products in order to increase the level of trust on their product. The regulatory bodies should also regulate the traditional medicine practitioners in terms of where the herbal products are prepared and packaged. The 
0.563 value is greater than 0.05 , we therefore concluded that there was no statistically significant difference between the herbal and the orthodox survey.

Financial support and sponsorship: Nil.

Conflict of Interests: There are no conflicts of interest.

\section{REFERENCES}

Abuja geographical information services (AGIS). 2004. Map of Abuja and it environments available at http://fcda.gov.ng/index.php? Option $=$ com content $\&$ view $=$ article $\&$ id $=32 \&$ item id $=68$.

Anonymous 1986. Herbal medicines-safe and effective? Drug Ther Bull. 24: 97-100.

Barnes J. Quality, efficacy and safety of complementary medicines: fashions, facts and the future. Part1. Regulation and Quality. Br. J Clin. Pharmacol. 2003; 55(3): 226-233.

Bodecker GC. Traditional health systems and public policy: renewal, research and international support. Journal of alternative and complement Medicine.1995; 1:102.

Vickers A, Zollman C. ABC of complementary medicine: herbal medicine. Br Med J. 1999; 319: 1050

ContableS, Ham A, Pirmohamed M. Herbal medicines and acute medical emergency admissions to hospital (letter to the editors). Br. J chin. Pharmed. 2007; 63: 247-248

Elujoba AA. 1998. Pharmacognostical standardization of herbal medicine: Standardization and utilization of herbal medicine: Challenges of the 21 st century. Proceedings of the 1st International Workshop on Herbal Medicinal Products, Nov. 22-24, Ibadan, Nigeria; 30-43.
King AR, Flint S, RussettFS, Generali JA, Graver DW. Evaluation and implications of natural product use in preoperative patients: a retrospective review BMC complement altern Med. 2009; 9:38

Langmead L, RamptonDS. 2001. Academic Department of Adult \& Pediatric Gastroenterology, St Bartholomew's \& the Royal London School of Medicine \& Dentistry, London, UK.

Moody JO. 2007. Traditional Medicine. Paper Delivered at the Mandatory Continuing Professional Development (MCPD) Programme, Module V, Faculty Pharmacy, University of Ibadan, Nov. 21-22. 1-6.

Ohuabunwa SI. 1998. Modern Herbal Medicinal Products. Proceedings of 1st International Workshop on Herbal.

WHO. 1996. Final report of the seminar on the use of medicinal plants in health care. WHO (WPRO Publication), Tokyo.

\section{How to cite this article:}

Mustapha KB, Kirim RA, Ibrahim JA, Onuche PO, BakareOdunola TM. Perception of Use of Herbal and Orthodox Medicines in Parts of Abuja: A Pilot Study. J App Pharm Sci, 2016; 6 (09): 128-132. 